\title{
Asymmetric attachment and functionalization of plasmonic nanoparticles on ceramic interfaces
}

\author{
Daniel Stadler ${ }^{1} \cdot$ Shifaa Mohammed Siribbal $^{1} \cdot$ Isabel Gessner $^{1} \cdot$ Senol Öz $^{1} \cdot$ Shaista llyas $^{1} \cdot$ Sanjay Mathur $^{1}$
}

Received: 13 October 2017 / Accepted: 9 January 2018 / Published online: 12 February 2018

(c) The Author(s) 2018. This article is an open access publication

\begin{abstract}
The demands for materials that integrate more than one functional imaging or therapeutic unit are of increasing interest for biomedical applications. Here, we present the step-by-step preparation of asymmetric and optically active particles, namely, $\mathrm{Gd}_{2} \mathrm{O}_{3} @ \mathrm{Ag}, \mathrm{Gd}_{2} \mathrm{O}_{3} @ \mathrm{Au}, \mathrm{SiO}_{2}-\mathrm{N}_{3} @ \mathrm{Au}$, and $\mathrm{SiO}_{2}-\mathrm{SH} @ \mathrm{Au}$. Successful attachment of plasmonic nanoparticles to the surface of metal-oxide spheres without necessity of a potentially toxic inter-adhesive layer was proven by optical methods as well as X-ray photoelectron spectroscopy. The combination of optical and magnetic properties as present in $\mathrm{Gd}_{2} \mathrm{O}_{3} @$ $\mathrm{Ag}$ and $\mathrm{Gd}_{2} \mathrm{O}_{3} @ \mathrm{Au}$ Janus-type particles leads to dual-imaging probes for optical and magnetic resonance imaging. In addition, functional groups, such as azide groups, were linked to the surface of silica particles previous to Au nanoparticle attachment. Subsequent site-selective click reactions with 5-FAM were successfully performed as demonstrated by UV-Vis measurements. All described systems exhibited excellent long-term stability and can, therefore, be considered as promising candidates for theranostic applications.
\end{abstract}

\section{Graphical abstract}

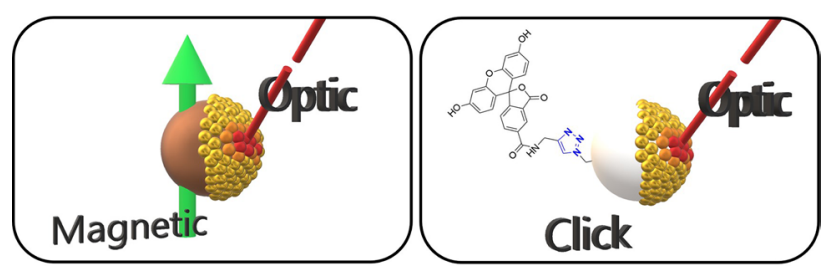

Keywords Theranostics · Janus particles · Optical materials $\cdot$ Sputter deposition $\cdot$ Magnetic

Daniel Stadler and Shifaa Mohammed Siribbal contributed equally to this work.

Electronic supplementary material The online version of this article (https://doi.org/10.1007/s40097-018-0252-y) contains supplementary material, which is available to authorized users.

Sanjay Mathur

sanjay.mathur@uni-koeln.de

1 Department of Chemistry, Inorganic Chemistry, University of Cologne, Greinstrasse 6, 50939 Cologne, Germany

\section{Introduction}

The rapid evolution of nanoprobe applications in medicine demands advanced control over their intrinsic properties, which usually rely on the composition and shape of nanoprobes, as well as their proper functional surface modification [1]. Beside conventional preparation methods, such as solvothermal reactions, a variety of specialized protocols for nanocluster formation, e.g., using nanoreactors [2] are reported in the literature. In the field of biomedicine, nanoparticles (NPs) have become more and more important. Besides drug delivery applications, NPs are widely used for in vivo imaging techniques. To date, a variety of nanocolloidal systems are reported for optical bioimaging applications 
including rare-earth-doped nanoparticles [3], carbon nanodots [4], and metallic nanoshells [5]. While optical methods are range limited by light absorption of the examined body, and still, in need of invasive techniques, magnetic resonance imaging (MRI) is suitable for non-invasive imaging of malignant tissues. Being well-established as a strong $\mathrm{T}_{1}$ contrast agent $[6,7], \mathrm{Gd}_{2} \mathrm{O}_{3} \mathrm{NPs}$ bare a large magnetic moment of $7.94 \mu \mathrm{B}$ per $\mathrm{Gd}^{3+}$ ion, leading to a high longitudinal relaxivity of nearby water protons.

In general, molecular surface modifications of these particles can be performed by grafting methods [8], whereas biomedically useful surface modifications are mostly achieved via cycloaddition reactions, e.g., the famous click reaction [9-11], biotin-streptavidin interactions [12], and carbodiimide coupling reactions [13]. By these techniques, immobilization of antibodies, drugs, and vitamin units is achieved and widely reported in the literature [14-16]. Among a broad variety of surface grafting techniques, click reactions have emerged as one of the most commonly used functionalization strategies based on their high selectivity, the tolerance of a wide range of solvents and $\mathrm{pH}$ and their high yield even at room temperature [11]. The most prominent type of click reaction is the copper(I) catalyzed alkyne-azide click reaction which leads to the formation of a stable triazole ring. While the non-catalyzed Huisgen reaction produces an unspecific mixture of 1,4 and 1,5-disubstitution products, only 1,4 disubstituted 1,2,3-triazoles are formed when copper is employed as catalyst. Besides alkyne-azide coupling reactants, thiol-ene and thiol-yne click reactions offer additional copper-free pathways for surface chemistry. As an example, Zhang et al. reported a successful immobilization of boronic acid on magnetic NPs for side-selective capture of glycoproteins [17]. In fact, it has been shown that click reactions offer larger efficiencies than their prominent carbodiimide counterparts [15]. However, all these techniques lack a chemical side selectivity, which results in an unspecific localization of ligands on the particle surface. The attachment of two types of ligands to one particle thus still remains a major challenge. In this regard, Janus-type particles, which possess an asymmetric geometry, have found increasing attention during the last years. The combination of two material types in one particle offers beneficial physicochemical properties that can help to overcome limitations of one material. For example, an asymmetric combination of plasmonic and magnetic characteristics in one particle provides a novel platform for multimodal imaging and therapeutic applications. Simply spoken, only one injection would be needed for detection of cancer by MRI and a direct treatment of infected cells by photothermal therapy [18]. Janus-type particles have been applied as sensors [19, 20], catalysts [21], emulsifiers [22, 23], and building blocks for the formation of self-assembled superstructures [24], reports on an asymmetric combinationof plasmonic and magnetic properties for biomedical applications are rather rare [25]. In addition, a variety of preparation methods are presented for polymeric Janus particles, as reviewed extensively [25, 26], while a controllable preparation of biocompatible ceramic NPs, baring asymmetric functionalities is still missing. Even though a simple sputtering approach of gold NPs on immobilized silica particles was already presented in 1988 by Casagrande et al. [27]., shell stability could only be achieved by adhesive layers, such as $\mathrm{Ti} / \mathrm{W}$ alloy or $\mathrm{Ni}$, at the metal-oxide interface $[28,29]$. However, due to the cytotoxic properties of these metals, these interlayers lower the biomedical applicability of the particles dramatically and limit their possible application for in vivo studies. In this approach, we present a simple method for the preparation of metal-oxide particles which can be surface decorated with plasmonic silver or gold nanoparticles. Unlike the procedures reported in the literature, no metallic inter-adhesive layers are needed for the formation of long-term stable dispersions of Janus-type functionalized ceramic particles. Instead, oxidative surface activation techniques, such as ozone treatment were used for an increased shell stability.

Shape-controlled particles were designed to have two non-centrosymmetric oriented functionalities. Plasmonic properties were added to previously prepared phase pure $\mathrm{Gd}_{2} \mathrm{O}_{3}$ and functionalized silica particles by $\mathrm{Ag}$ and $\mathrm{Au}$ NPs deposition without any metallic interlayers. Using a "stepby-step" approach, consisting of particle immobilization, magnetron sputtering and dispersing, each part of the synthesis can be separately controlled depending on the desired application. Therefore, the presented technique offers a large flexibility in variation of the core, shell, and functionalization. The suitability of as-prepared Janus-type particles for potential biomedical applications was demonstrated by attaching a dye as model molecule selectively to the silicaside via click reaction. To the best of our knowledge, we are the first to present a long-term stable Janus-type particle system without any additional interlayers in between the oxide and noble metal, prepared by a simple sputtering technique. A schematic drawing of the preparation process is given in Fig. 1.

\section{Experimental part}

\section{Materials}

FTO glass substrates ( $7 \Omega / \mathrm{sq}$ ) were received from Pilkington, $3^{\prime \prime} \times 5$ glass substrates were received from VWR and cut into $1 \times 1 \mathrm{~cm}$ pieces. Gold and silver sputter targets (99.999\% purity) were bought from Quorum Technologies Ltd and sputtered using a Quorum TS 150. 5-Carboxyfluorescein-alkyne (5-FAM) was purchased from Lumiprobe 


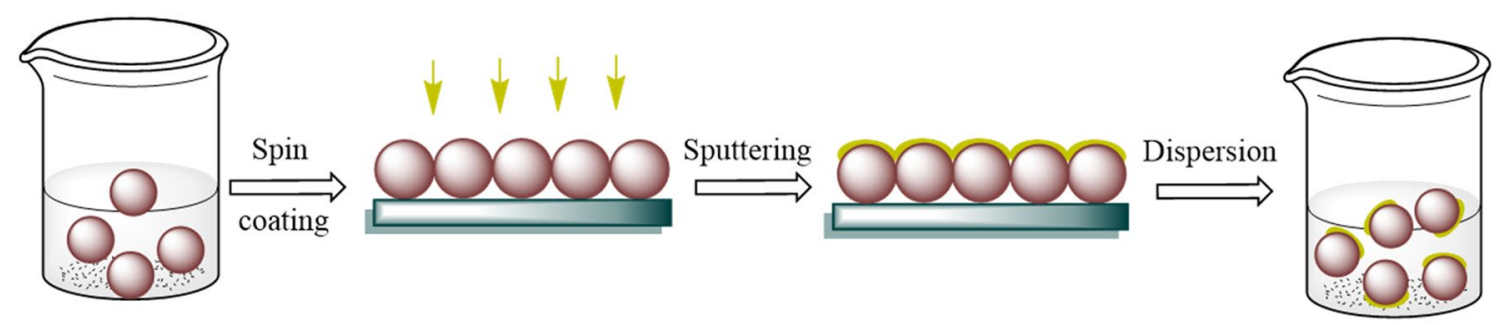

Fig. 1 Schematic drawing of the preparation process, consisting of spin coating, sputtering, and redispersing

$\mathrm{GmbH}$. All other chemicals used in this work were purchased from Sigma-Aldrich and used as received.

\section{Synthesis of spherical $\mathrm{Gd}_{2} \mathbf{O}_{3}$ particles}

The gadolinium oxide particles were prepared following the homogeneous precipitation method using urea [30]. A Gd( $\left(\mathrm{NO}_{3}\right)_{3}$ solution $(1 \mathrm{~mL}, 1 \mathrm{M})$ was placed in a $100 \mathrm{ml}$ round bottom flask and was further diluted with $50 \mathrm{~mL}$ of water. Urea $(2 \mathrm{~g})$ was added to the flask and the mixture was stirred for $2 \mathrm{~h}$ at room temperature to form a homogeneous solution. Afterwards, reaction temperature was increased to $90{ }^{\circ} \mathrm{C}$ for $2 \mathrm{~h}$ to form a white milky dense solution. The particles were separated using a centrifuge at $11,000 \mathrm{rpm}$ for $20 \mathrm{~min}$, and washed three times with water, water-ethanol and ethanol. Finally, the particles were dried in an oven at $60{ }^{\circ} \mathrm{C}$ overnight. The particles were further annealed at $800{ }^{\circ} \mathrm{C}$ for $150 \mathrm{~min}\left(600{ }^{\circ} \mathrm{C} / \mathrm{h}\right)$ to obtain $\mathrm{Gd}_{2} \mathrm{O}_{3}$ particles.

\section{Synthesis of silica spheres $\left(\mathrm{SiO}_{2}\right)$}

Silica particles were prepared using the Stöber method [31]. In detail, ethanol $(90.00 \mathrm{~mL})$, deionized water $(32.50 \mathrm{~mL})$, and $\mathrm{NH}_{4} \mathrm{OH}$ solution $(2.25 \mathrm{~mL}, 28 \%)$ were mixed together at $25{ }^{\circ} \mathrm{C}$. Tetraethyl orthosilicate (TEOS, $7.75 \mathrm{~mL}, 35 \mathrm{mmol}$ ) was added under vigorous stirring and the dispersion was stirred for $2.5 \mathrm{~h}$. Afterwards, the particles were collected by centrifugation $(11,000 \mathrm{rpm}, 15 \mathrm{~min})$. The precipitated particles were redispersed in ethanol and water (1:1), followed by collection of the particles by centrifugation. This procedure was repeated once. Finally, the particles were dispersed in deionized water $(15 \mathrm{~mL})$.

\section{Formation of azide functionalized silica spheres $\left(\mathrm{SiO}_{2}-\mathrm{N}_{3}\right)$}

Azide functionalized silica spheres were prepared by surface treatment of the particles with 11-bromoundecyltrichlorosilane [16]. The previously prepared $\mathrm{SiO}_{2}(200 \mathrm{mg}$, $3.33 \mathrm{mmol}$ ) sub-micrometer spheres were dispersed in a mixture of toluene (anhydrous, $50 \mathrm{~mL}$ ) and dimethyl formamide (DMF, anhydrous, $5 \mathrm{~mL}$ ), which was added to increase the dispersibility of the particles. Afterwards, the dispersion was heated up to $60{ }^{\circ} \mathrm{C}$ and 11-bromoundecyltrichlorosilane ( $422 \mu \mathrm{L}, 1.44 \mathrm{mmol}$ ) was added rapidly. The reaction proceeded at $60{ }^{\circ} \mathrm{C}$ for additional $19 \mathrm{~h}$. Particles were separated by centrifugation and washed at least four times with toluene. The final particles were dried for $12 \mathrm{~h}$ at ambient conditions. Afterwards, the bromine functionalized particles were dispersed in DMF $(5 \mathrm{~mL})$ and $\mathrm{NaN}_{3}(200 \mathrm{mg}$, $3.07 \mathrm{mmol}$ ) was added. The reaction was stirred for $40 \mathrm{~h}$ at $25^{\circ} \mathrm{C}$. Collection of the particles was performed with a centrifuge (4400 rpm, $15 \mathrm{~min}$ ), followed by five washing steps. Finally, the particles were dried for $12 \mathrm{~h}$ at $25^{\circ} \mathrm{C}$.

\section{Formation of thiolated silica spheres $\left(\mathrm{SiO}_{2}-\mathrm{SH}\right)$}

Thiol functionalized silica spheres were prepared according to Claesson et al. [32]. In this procedure, 3-mercaptopropyl trimethoxysilane (MPTMS, $1.5 \mathrm{~mL}, 7.16 \mathrm{mmol}$ ) was added to an aqueous dispersion $(70 \mathrm{mg} / \mathrm{mL})$ of silica spheres. The reaction proceeded for $45 \mathrm{~min}$ at ambient conditions. Afterwards, the solution was heated to $80^{\circ} \mathrm{C}$ for $60 \mathrm{~min}$. The particles were collected via centrifugation $(9000 \mathrm{rpm}, 10 \mathrm{~min}$ ) and washed three times with ethanol. Finally, the particles were dispersed in ethanol $(40 \mathrm{~mL})$.

\section{Substrate preparation}

FTO and glass substrates were washed for 15 min each with acetone, deionized water with $2 \%$ Helmanex III soap, and isopropyl alcohol in an ultrasonic bath kept at $50{ }^{\circ} \mathrm{C}$. Before spin coating, the FTOs were treated with oxygen plasma for $15 \mathrm{~min}$ and the glass substrates were treated oxidatively in an UV-ozone cleaner (Dinier@, ELG 100 s) to remove any remaining organic impurities and to increase the surface wettability. All substrates were used directly after activation.

\section{Preparation of Janus-type $\mathrm{Gd}_{2} \mathrm{O}_{3} @ \mathrm{Ag}$ and $\mathrm{Gd}_{2} \mathrm{O}_{3} @$ Au particles}

The prepared $\mathrm{Gd}_{2} \mathrm{O}_{3}$ particles $(50 \mathrm{mg}$ ) were placed in an argon flushed vial equipped with a stirring bar and transferred to a nitrogen filled glovebox. Isopropanol (anhydrous, 
$600 \mu \mathrm{L}$ ) was added to form a homogeneous white dispersion stirred for $2 \mathrm{~h}$. FTO substrates were also transferred to the glovebox and each was coated with $\mathrm{Gd}_{2} \mathrm{O}_{3}$-isopropanol solution $(50 \mu \mathrm{L})$. Spin coating of substrates was performed with an acceleration rate of $800 \mathrm{rpm} / \mathrm{s}$ for $45 \mathrm{~s}$ at 1000 and $3000 \mathrm{rpm}$, respectively. The coated substrates were placed on a hot-plate at $100{ }^{\circ} \mathrm{C}$ to dry and ensure removal of solvent. Coated substrates were placed inside a sputtering machine. Silver and gold were sputtered onto the particles layer at a discharge current of $20 \mathrm{~mA}$ at $20 \mathrm{mbar}$ for 20 and $40 \mathrm{~s}$, respectively.

\section{Preparation of Janus-type $\mathrm{SiO}_{2}-\mathrm{N}_{3} @ \mathrm{Au}$ and $\mathrm{SiO}_{2}-$ SH@Au particles}

$\mathrm{SiO}_{2}-\mathrm{N}_{3}$ or $\mathrm{SiO}_{2}-\mathrm{SH}$ dispersion $\left(10 \mu \mathrm{L}, 70 \mathrm{mg} \mathrm{mL}^{-1}\right)$ was transferred onto an activated glass slide. The dispersion was allowed to cover the substrate completely and dried using a spin-coating technique. The dried sample was placed in the UV chamber for further $30 \mathrm{~min}$ and gold was sputtered onto the substrates $(20 \mathrm{~mA}, 30 \mathrm{~s})$. Finally, the particles were collected in ethanol $(4 \mathrm{~mL})$ by sonification.

\section{Covalent attachment of 5-FAM to $\mathrm{SiO}_{2}-\mathrm{N}_{3} @ \mathrm{Au}$ particles}

$\mathrm{CuSO}_{4}(12.5 \mathrm{mg}, 0.07 \mathrm{mmol})$, L-histidine $(19.5 \mathrm{mg}$, $0.13 \mathrm{mmol}$ ), and sodium ascorbate $(49 \mathrm{mg}, 0.25 \mathrm{mmol})$ were each dissolved in water $(250 \mu \mathrm{L})$. Afterwards, $\mathrm{CuSO}_{4}$, a 5-FAM-alkyne solution $(100 \mu \mathrm{L}, 5 \mathrm{mM})$, histidine and sodium ascorbate were mixed subsequently under stirring in a $10 \mathrm{~mL}$ reaction vessel. Finally, the aqueous dispersion of $\mathrm{SiO}_{2}-\mathrm{N}_{3} @$ Au particles $\left(1 \mathrm{~mL}, \sim 7 \mathrm{mg} \mathrm{mL}^{-1}\right)$ was added and the reaction was allowed to proceed for $4 \mathrm{~h}$. The final particles were collected via centrifugation (1600 rpm, $15 \mathrm{~min}$ ) and washed five times. Finally, the particles were dried for $14 \mathrm{~h}$ under ambient conditions.

\section{Characterization}

All measurements were performed under ambient conditions and in neutral $\mathrm{pH}$. X-ray diffraction (XRD) analysis of $\mathrm{Gd}_{2} \mathrm{O}_{3}$ particles was carried out on an STOE-STADI MP diffractometer equipped with a $\mathrm{Cu}(R=0.15406 \mathrm{~nm})$ source and operating in transmission mode. A scan rate of $0.05 \%$ was applied to record the pattern in the $2 \theta$ range of $10^{\circ}-80^{\circ}$. Scanning electron micrographs were performed on an FEI Nova Nano SEM 430. Energy-dispersive X-ray spectroscopy was performed on an Apollo X EDAX. (Working distance $5 \mathrm{~mm}$; entry angle $35^{\circ}$ ). X-ray photoelectron spectroscopy (XPS) was performed on an ESCA M-Probe (Surface Science Instruments) using Al-K $\alpha$-radiation (1486.6 eV). TEM measurements were carried out using a ZEISS LEO 902 microscope operating at $120 \mathrm{kV}$ with $\mathrm{LaB}_{6}$ cathode in a bright field mode. The samples were deposited onto a carbon coated copper grid. The mean diameter was statistically determined from a varying number of particles from bright field micrographs. Dynamic light scattering (DLS) and $\zeta$-potential measurements were performed with a Malvern Instruments Zetasizer Nano ZS (operating wavelength: $633 \mathrm{~nm}$ ). All values and standard deviations presented here were calculated out of five measurements. Measurements were performed in polystyrene cuvettes. FT-IR spectra were collected using a Perkin Elmer Spectrum 400. Powder-like samples were measured in the range of $4000-400 \mathrm{~cm}^{-1}$. For Raman spectroscopy, a Horiba Jobin-Yvon spectrometer in triple subtractive mode equipped with a liquid nitrogencooled CCD detector, $1800 \mathrm{gr} / \mathrm{mm}$ gratings, and a laser wavelength of $532 \mathrm{~nm}$ was used. The incident beam angle was $45^{\circ}$ concerning the $\mathrm{a}-\mathrm{b}$ plane of the sample. Before the measurement, the powder-like sample was placed between two previously cleaned microscopic glass slides.

\section{Results and discussion}

\section{Particle preparation and functionalization}

The hydrogen-carbonate precursor $\mathrm{Gd}(\mathrm{OH}) \mathrm{CO}_{3} \cdot \mathrm{H}_{2} \mathrm{O}$ was prepared following the urea-based homogeneous precipitation method, established by Matijevic and coworkers in 1988 [30]. While refluxing an aqueous solution of $\mathrm{Gd}^{3+}$ salt, urea serves as a precipitating agent for the $\mathrm{Gd}^{3+}$ ions by shifting the $\mathrm{pH}$ value into basic conditions due to self-decomposition at elevated temperature. The $\mathrm{Gd}(\mathrm{OH}) \mathrm{CO}_{3} \bullet \mathrm{H}_{2} \mathrm{O}$ precursor was further subjected to thermal treatment at $850^{\circ} \mathrm{C}$ for $2 \mathrm{~h}$. XRD analysis (Fig. 2a) revealed a highly crystalline $\mathrm{Gd}_{2} \mathrm{O}_{3}$ phase, indicating a successful conversion of the $\mathrm{Gd}(\mathrm{OH})$ $\mathrm{CO}_{3} \cdot \mathrm{H}_{2} \mathrm{O}$ precursor. Diffration peaks were observed at $20.32^{\circ}, 28.86^{\circ}, 33.39^{\circ}, 47.92^{\circ}, 56.75^{\circ}, 61.94^{\circ}$, as well as at $71.07^{\circ}$ and indexed to the (211), (222), (440), (444), (622), (640), and (811) planes in cubic space group Ia-3 (No. 206), respectively. No crystalline secondary phases or impurities could be detected within the detection limit.

The electron microscope images in Fig. $2 b$ illustrate the size and morphology of the $\mathrm{Gd}(\mathrm{OH}) \mathrm{CO}_{3} \cdot \mathrm{H}_{2} \mathrm{O}$ particles before thermal treatment. As synthesized particles were spherical in shape, nearly, monodisperse and homogeneously distributed with average size of $100-120 \mathrm{~nm}$, fitting the demand of biological application. Furthermore, the particles' uniform surface is preferred for targeting ligands' conjugation and imaging probes [33]. It is noteworthy that the particles did not show any changes in size or morphology after calcination, as clearly presented in Fig. 2c. Even for a rapid heating rate of $10{ }^{\circ} \mathrm{C} / \mathrm{min}$, the particles maintained their regular morphology in contrast to the previous work 

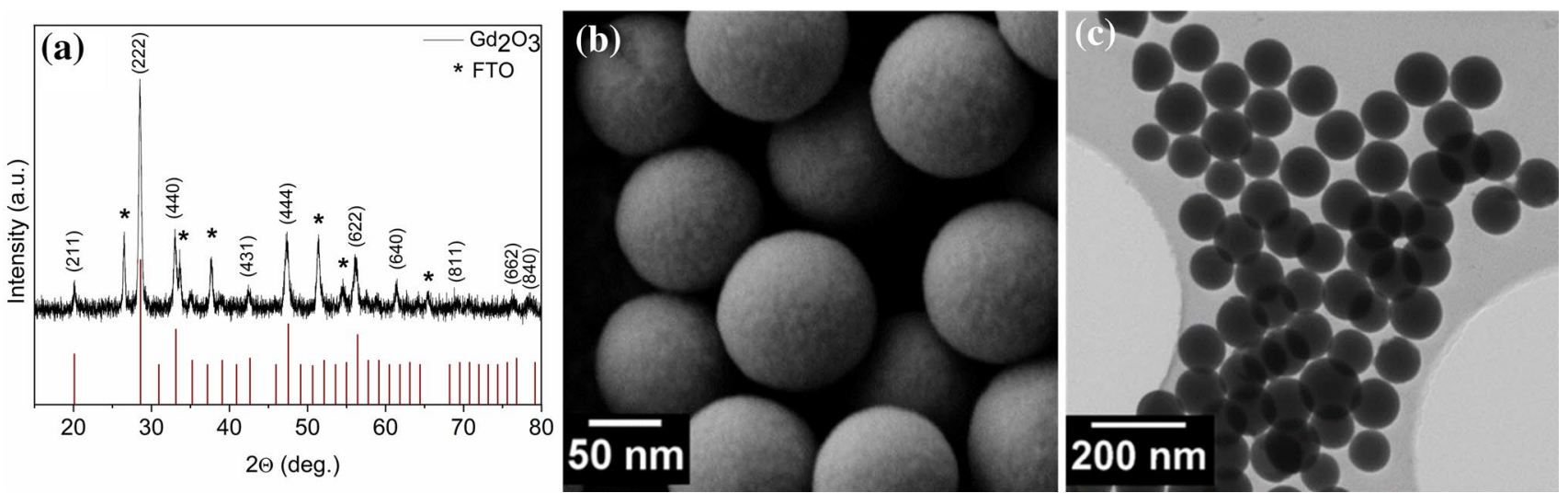

Fig. 2 a XRD pattern for spin-coated $\mathrm{Gd}_{2} \mathrm{O}_{3}$ particles (ref.: JCPDS C12-0797) on FTO substrate (labelled as *, JCPDS C41-1445), demonstrating a phase pure formation of $\mathrm{Gd}_{2} \mathrm{O}_{3} \mathbf{b}$ SEM and $\mathbf{c}$ TEM images of $\mathrm{Gd}_{2} \mathrm{O}_{3}$ particles, presenting a spherical morphology of the obtained particles

of Di et al., reporting an optimal heating rate of $2{ }^{\circ} \mathrm{C} / \mathrm{min}$ to prevent shrinkage of the particles and maintaining their original morphology [34].

Silica particles with an average hydrodynamic diameter of 170.6 (7) nm, as proven by DLS measurements, were prepared according to the Stöber method [31]. FT-IR measurements (see Fig. 3a) revealed characteristic silica bands at $1052 \mathrm{~cm}^{-1}$ (Si-O-Si sym. stretching), $1200 \mathrm{~cm}^{-1}$ (Si-O-Si asym. stretching), $935 \mathrm{~cm}^{-1}$ (Si-O, non-bridging), $784 \mathrm{~cm}^{-1}$ (Si-O-Si, bending), and $445 \mathrm{~cm}^{-1}$ (O-Si-O, bending) [35]. Free hydroxyl functions were detected at $3350 \mathrm{~cm}^{-1}$, while physically adsorbed water and ethanol molecules were measured at 1632 and $1458 \mathrm{~cm}^{-1}$, respectively. The particles stability in dispersion was analyzed as $\zeta$-potential and resulted in an excellent value of - 49.3 (4) $\mathrm{mV}$, indicating the formation of a long-term stable dispersion [36]. After surface treatment, a successful formation of $\mathrm{SiO}_{2}-\mathrm{N}_{3}$ spheres was clarified using FT-IR spectroscopy.

As presented in Fig. 3a, a clear signal was visible at $2102 \mathrm{~cm}^{-1}$, related to the successful attachment of the azide onto the particles surface $[16,35]$. DLS analysis proves the formation of particles with an average hydrodynamic diameter of 229 (4) nm and an average $\zeta$-potential of - 19 (2) $\mathrm{mV}$, where the replacement of negatively charged hydroxyl functions by azide groups resulted in the observed shift towards positive values of the $\zeta$-potential.

For obtaining thiol functionalized silica particles, potentially usable for thiol-ene coupling, previously prepared silica particles were surface functionalized with MPTMS [32]. Raman spectroscopy proved a successful attachment of the thiol function on the particles surface (Fig. 3b). The bands related to the thiol group are measured at $2571 \mathrm{~cm}^{-1}$ (marked in red, S-H bond stretching), $1261 \mathrm{~cm}^{-1}$ (wag vibration of the $\mathrm{S}-\mathrm{CH}_{2}$ group), and $650 \mathrm{~cm}^{-1}$ (C-S bond stretching) [37], while $\mathrm{C}-\mathrm{H}$ bands were observed at $2928 \mathrm{~cm}^{-1}$ (antisymmetric $\mathrm{C}-\mathrm{H}$ stretching of the $\mathrm{CH}_{2}$ groups) and $2894 \mathrm{~cm}^{-1}$ (symmetric $\mathrm{C}-\mathrm{H}$ stretching of the $\mathrm{CH}_{2}$ groups), as well as at $1431 \mathrm{~cm}^{-1}\left(\mathrm{CH}_{2}\right.$ deformation). This indicates that nonoxidized thiol groups are present on the surface. Therefore, an immobilization of target molecules via thiol-ene reactions should be possible. The average hydrodynamic diameter of $\mathrm{SiO}_{2}-\mathrm{SH}$ particles was measured as 267 (3) $\mathrm{nm}$ by DLS analysis, whereas the obtained $\zeta$-potential was - 45 (1) $\mathrm{mV}$. As in case of silica particles, this negative value indicates a long-term dispersability and a negative surface charge consisting of deprotonated thiol groups.

\section{Janus particle formation}

For controllable asymmetric functionalization, previously described particles were immobilized on carrier substrates using spin-coating technique. The substrates were treated either with oxygen plasma or UV-ozone prior to particle deposition, providing a good solvent wettability and easy removal of organic residues from the substrate surface. The coated substrates were dried subsequently to remove any remaining solvent. A thin layer $(<10 \mathrm{~nm})$ of silver and gold was deposited onto the surface of the NPs via magnetron sputtering at various discharge currents and times, depending on the material. The resulting coated particles were then released from the supporting substrate and redispersed in an aqueous solution by immersing the substrate under sonication for a few seconds.

The XRD patterns for $\mathrm{Gd}_{2} \mathrm{O}_{3} @ \mathrm{Ag}$ and $\mathrm{Gd}_{2} \mathrm{O}_{3} @ \mathrm{Au}$ particles are presented in Fig. 4a, c, respectively. Diffraction peaks with the highest intensity for metallic silver and gold were observed at $38.04^{\circ}(\mathrm{Ag})$ and $38.10^{\circ}(\mathrm{Au})$, corresponding to the (111) plane of cubic (fcc) lattice and in excellent agreement with the standard powder diffraction cards of gold and silver (see Fig. 4a, c). The dispersions of hetero-structured particles presented monodisperse size distribution, as confirmed by SEM, maintaining their 

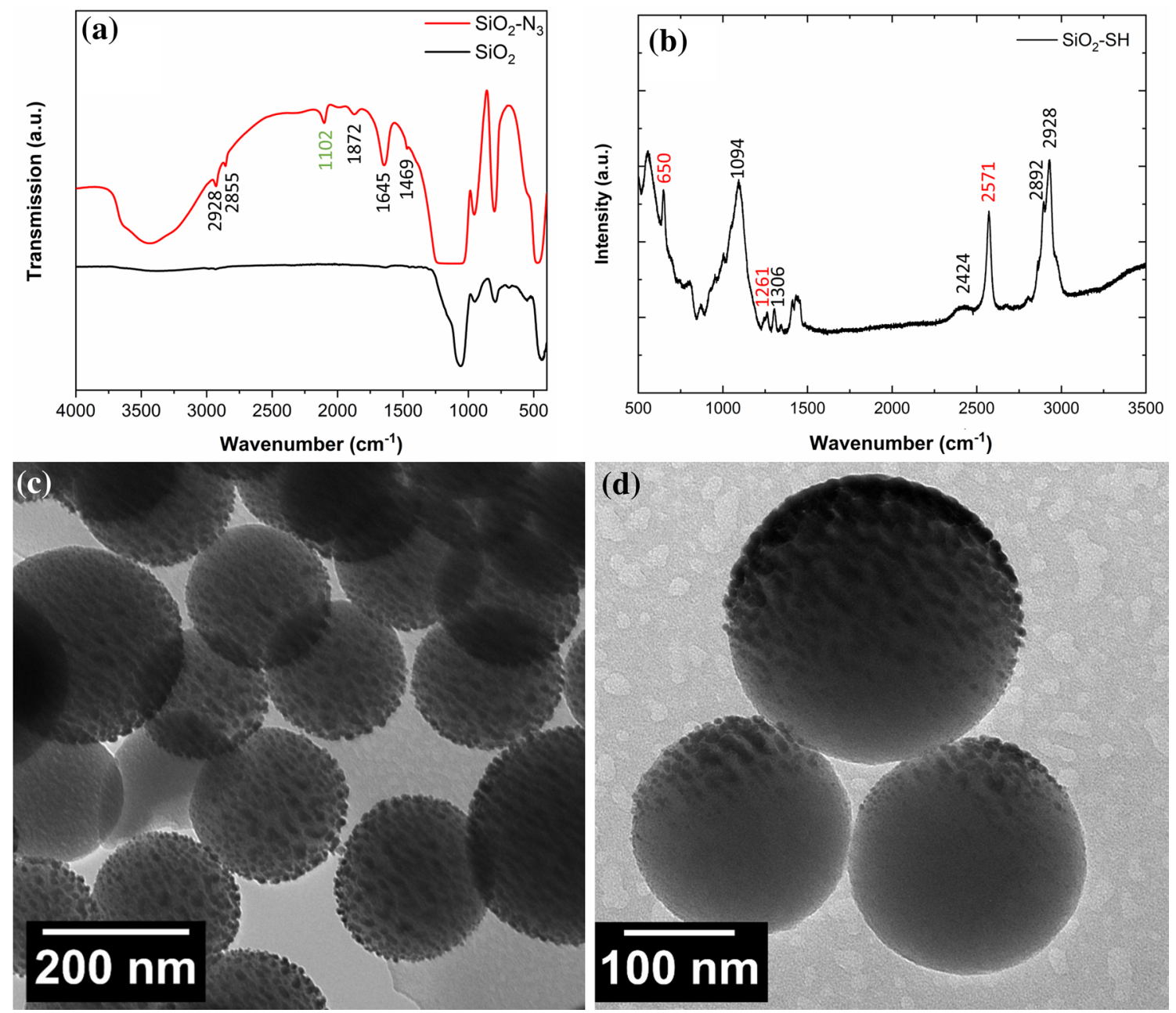

Fig. 3 a FT-IR spectrum of prepared silica spheres (grey) and azide functionalized silica spheres (red, azide band is marked in green), and $\mathbf{b}$ Raman spectrum of thiolated silica spheres (characteristic thiol bands are marked in red), c TEM micrographs of $\mathrm{SiO}_{2}-\mathrm{N}_{3} @ \mathrm{Au}$ particles, and d TEM micrographs of $\mathrm{SiO}_{2}-\mathrm{SH} @ \mathrm{Au}$ particles. All char-

original spherical shape after asymmetric functionalization, as clearly visible for $\mathrm{Gd}_{2} \mathrm{O}_{3} @ \mathrm{Ag}$ and $\mathrm{Gd}_{2} \mathrm{O}_{3} @ \mathrm{Au}$ particles in Fig. 4b, d, respectively. The noble metal layer was localized asymmetrically on one side of the spheres, whereas the backside of $\mathrm{Gd}_{2} \mathrm{O}_{3}$ particles, protected by the substrate, remained non-functionalized. While cluster formation of $\mathrm{Ag}$ and higher surface roughnesses, providing oxide formation, are demonstrated for $\mathrm{Gd}_{2} \mathrm{O}_{3} @ \mathrm{Ag}, \mathrm{Au}$ functionalization resulted in a smoother film formation, as visible in Fig. 4d. Furthermore, no Au particles are visible on the $\mathrm{Gd}_{2} \mathrm{O}_{3}$ particles surface in contrast to the $\mathrm{Gd}_{2} \mathrm{O}_{3} @$ Ag particles. As for $\mathrm{Gd}_{2} \mathrm{O}_{3}$ Janus particles, no unattached gold NPs were observed for $\mathrm{SiO}_{2}-\mathrm{N}_{3} @ \mathrm{Au}$ and $\mathrm{SiO}_{2}-\mathrm{SH} @$ $\mathrm{Au}$. However, isolated Au NPs were measured at the surface, having an average particle diameter of $8 \pm 2 \mathrm{~nm}$, as determined by TEM micrographs (Fig. 3c, d). acteristic absorption bands for azide and thiol functionalization were detected in IR and Raman spectra, respectively. Furthermore, a clear asymmetric location of gold NPs on the particles is demonstrated in TEM images

In fact, all samples showed long-term stability even after removal from the substrate surface, as confirmed by SEM measured for the same particle dispersions after weeks (Figure S2). It can be clearly seen that the sputtered metallic clusters adhere strongly to the $\mathrm{Gd}_{2} \mathrm{O}_{3}$ surface and the dispersion of particles using ultrasonic bath did not deform the spheres or detached metallic NPs. Moreover, it has been reported that the deposition of noble metals on metal-oxide surfaces needs an adhesion layer such as Ti/W alloy or $\mathrm{Ni}$, to obtain an intimate and long lasting contact of the film $[28,29]$. However, it should be noted that asymmetrical capping of the presented particles with Ag and Au was achieved without any additional interlayer support.

In case of $\mathrm{Gd}_{2} \mathrm{O}_{3}$-based Janus-type particles, a red shift of surface plasmon resonance of the silver and gold due to direct contact with the oxide was observed. The UV-Vis 

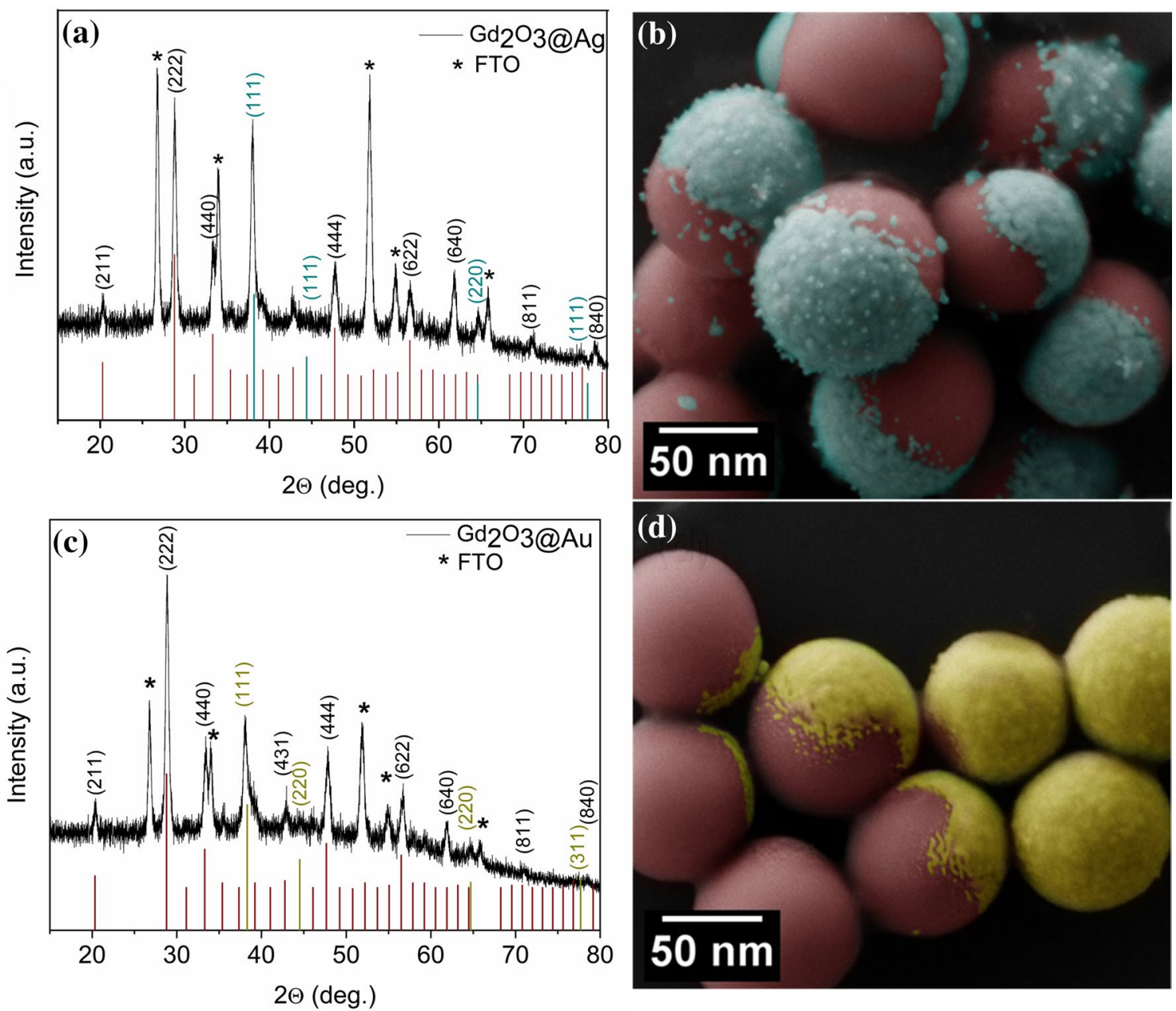

Fig. 4 a XRD profile for spin-coated $\mathrm{Gd}_{2} \mathrm{O}_{3}$ particles on the surface of the FTO substrate after sputtering of Ag (JCPDS C87-0720), b colorized SEM images for acorn-like $\mathrm{Gd}_{2} \mathrm{O}_{3} @ \mathrm{Ag}$ particles, c after sputtering of Au (JCPDS C04-0784), and d colorized SEM images for $\mathrm{Gd}_{2} \mathrm{O}_{3} @ \mathrm{Au}$ particles. A clear asymmetric decoration of metallic $\mathrm{Ag}$ and $\mathrm{Au}$ on the $\mathrm{Gd}_{2} \mathrm{O}_{3}$ is clarified by XRD, whereas SEM images revealed a rougher shell in case of Ag NP immobilization. In contrast, decoration of carrier particles resulted in smoother shell formation absorption spectrum of $\mathrm{Gd}_{2} \mathrm{O}_{3} @ \mathrm{Ag}$ Janus-type particles in Fig. 5a shows two absorption bands with maxima located at 388 and $529 \mathrm{~nm}$, while gold plasmon bands appeared at 567 and $525 \mathrm{~nm}$ for $\mathrm{Gd}_{2} \mathrm{O}_{3} @$ Au particles (Fig. 5b) and $\mathrm{SiO}_{2}-\mathrm{N}_{3} @ \mathrm{Au}$ Janus particles (Fig. 5c), respectively. In case of $\mathrm{SiO}_{2}-\mathrm{N}_{3} @ \mathrm{Au}$, the obtained result is in agreement with reports on immobilized Au NPs with comparable diameter. While unattached Au NPs are reported to have an absorption band at $519 \mathrm{~nm}$ [38], a red shift of absorption bands was reported for immobilized Au NPs on dielectric surfaces [39]. In addition, for $\mathrm{Gd}_{2} \mathrm{O}_{3} @ \mathrm{Ag}$ Janus particles (see Fig. 5a), isolated Ag NPs at the $\mathrm{Gd}_{2} \mathrm{O}_{3}$ particle surface could be measured at $388 \mathrm{~nm}$. As for $\mathrm{SiO}_{2}-\mathrm{N}_{3} @ \mathrm{Au}$ particles, a red shift of the absorption signal can be dedicated to an immobilization of plasmonic NPs at a dielectric interface. The second absorption at $529 \mathrm{~nm}$ can be attributed to the Ag shell. While equally sized Ag NPs should have an absorption band around $370 \mathrm{~nm}$, according to Mie theory [38], red shift caused by immobilization at dielectric interfaces does not explain the observed red shifts. Moreover, an increase in shell roughness is known to cause comparable red shifts [40]. As previously discussed, the obtained Ag shell has a significantly larger roughness in contrast to the Au shell. Consequently, a bigger red shift (red shift: $159 \mathrm{~nm}$ ) was measured in contrast to the smoother Au shell (red shift: $48 \mathrm{~nm}$ ). Therefore, UV-Vis measurements are in good agreement with already presented TEM images and additionally emphasize the Janus particles stability in dispersion. For $\mathrm{SiO}_{2}-\mathrm{SH} @$ Au particles, no plasmonic absorption was detected. Most likely, strong particle interactions caused the formation of agglomerates, leading to increased light scattering at these superstructures, hindering the absorption band of attached gold NPs. 

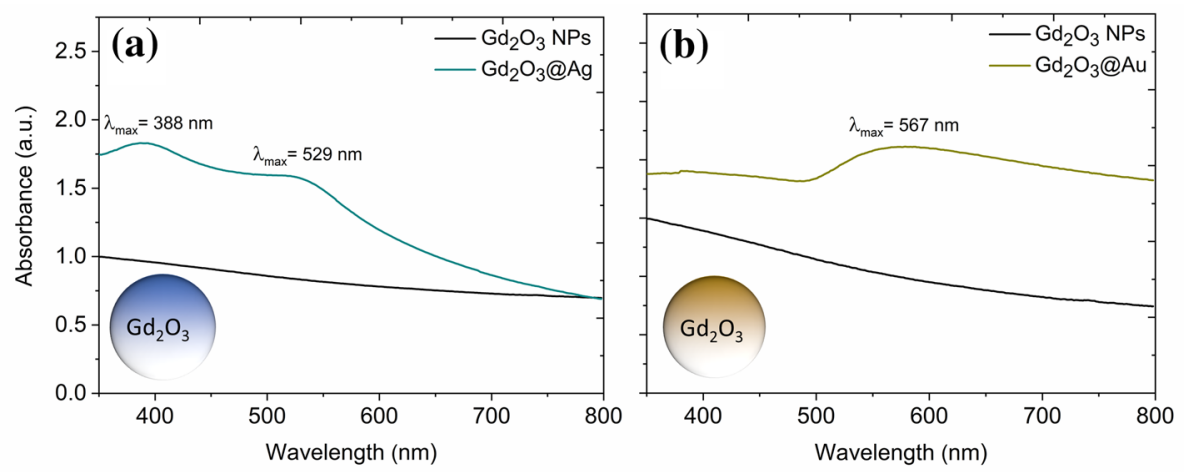

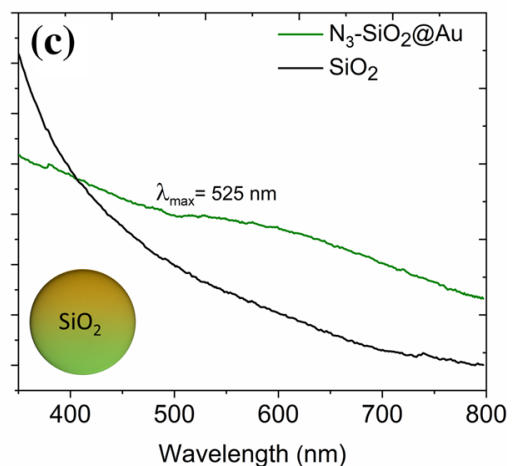

Fig. 5 UV-Vis measurements of a $\mathrm{Gd}_{2} \mathrm{O}_{3} @ \mathrm{Ag}$ particles, b $\mathrm{Gd}_{2} \mathrm{O}_{3} @$ $\mathrm{Au}$ particles, and $\mathbf{c} \mathrm{SiO}_{2}-\mathrm{N}_{3} @ \mathrm{Au}$ particles. In case of $\mathrm{Gd}_{2} \mathrm{O}_{3} @ \mathrm{Ag}$ particles, two absorption bands were measured corresponding to NP and shell formation on dielectric surfaces, whereas for $\mathrm{Gd}_{2} \mathrm{O}_{3} @ \mathrm{Au}$ particles, one absorption related to the noble metal shell is measured. For $\mathrm{SiO}_{2}-\mathrm{N}_{3} @ \mathrm{Au}$ particles, plasmonic absorption reliable to $\mathrm{Au} \mathrm{NP}$ immobilization at dielectric surfaces is detected

\section{XPS analysis of Janus-type $\mathrm{Gd}_{2} \mathrm{O}_{3}$ particles}

The composition and interaction between noble metals and ceramic host particles $\left(\mathrm{Gd}_{2} \mathrm{O}_{3}\right)$ were studied in detail by XPS, whereby high-resolution spectra were collected for detailed investigations of the interface between plasmonic surface and oxidic host particle. Charge correction was carried out in all spectra considering the charge shift of the $\mathrm{C}$ $1 \mathrm{~s}$ peak of adventitious carbon. An XPS survey spectrum of bare $\mathrm{Gd}_{2} \mathrm{O}_{3}$ NPs is presented in Figure S3, demonstrating a peak at $136.3 \mathrm{eV}$ which is related to the binding energy of $\mathrm{Gd} 4 \mathrm{~d}$, whereas the presence of adventitious carbon from atmospheric exposure after spin-coating procedure is confirmed by the $\mathrm{C} 1 \mathrm{~s}$ peak at $284.81 \mathrm{eV}$. The $\mathrm{O} 1 \mathrm{~s}$ surface peak at $530.31 \mathrm{eV}$ is dedicated to $\mathrm{Gd}_{2} \mathrm{O}_{3}$ and in good agreement with reported data of $\mathrm{O} 1 \mathrm{~s}$ in $\mathrm{Gd}_{2} \mathrm{O}_{3}$ at $530.6 \mathrm{eV}$ [41].

However, an increased atomic concentration of oxygen is explainable by the previously described attachment of $\mathrm{CO}_{2}$ after spin coating as well as oxygen from FTO carrier substrate. An Sn 3d peak is observed in all spectra due to the use of FTO as substrate. Figure 6a presents the XPS survey spectrum of $\mathrm{Gd}_{2} \mathrm{O}_{3} @ \mathrm{Ag}$ sample, demonstrating a noticeable decrease in signal intensity of the $\mathrm{Gd}, \mathrm{O}, \mathrm{C}$, and $\mathrm{Sn}$ peaks due to the complete coverage of host matrix by Ag. The high-resolution spectrum of the Ag $3 \mathrm{~d}$ region (Fig. 6b) showed two main peaks for $\mathrm{Ag} 3 \mathrm{~d} 5 / 2$ and $\mathrm{Ag} 3 \mathrm{~d} 3 / 2$ at 368.2 and $374.2 \mathrm{eV}$, respectively. Both $\mathrm{Ag} 3 \mathrm{~d}$ signals are located between Ag metal (368.3 and $374 \mathrm{eV}$ for $\mathrm{Ag} 5 / 2$ and $\mathrm{Ag} 3 / 2$, respectively) and $\mathrm{AgO}(367.8 \mathrm{eV}$ for $\mathrm{Ag} 3 \mathrm{~d} 5 / 2$ and $373.6 \mathrm{eV}$ for $\mathrm{Ag} 3 / 2$ ) [42, 43]. The $3 \mathrm{~d} 5 / 2$ and $3 \mathrm{~d} 3 / 2$ doublets for Ag in the fitting spectra have almost 3:2 peak area ratios, in agreement with the specific area ratios based on the degeneracy of $d$ spin state. Weaver et al. reported $\mathrm{Ag} 3 \mathrm{~d}$ peak shifts towards lower binding energy values upon oxidation [44]. Accordingly, our results (the position of Ag $3 \mathrm{~d}$ signal as well as the splitting of spin orbit component of almost $6.0 \mathrm{eV}$ ) are consistent with silver compounds and metallic silver which provide unambiguous information on the identity of the $\mathrm{Ag}$ oxidation state. Nevertheless, the $\mathrm{Ag}$ $3 \mathrm{~d}$ peaks have a full-width at half-maximum (FWHM) of $1.4 \mathrm{eV}$ which lies in between those reported for silver metal $(1.12 \mathrm{eV})$ and silver oxide $(1.8 \mathrm{eV})$ [42]. Moreover, plasmonic signals of metallic silver at 372 and $378 \mathrm{eV}$ for $3 \mathrm{~d} 3 / 2$ and $3 d 5 / 2$ are not resolved, most likely caused by a decrease in $\mathrm{Ag}$ amount due to oxidation, as clearly demonstrated in the XPS spectra, as presented in Fig. 6b. Indicated by peak position and FWHM, a mixture of $\mathrm{AgO}$ and $\mathrm{Ag}$ metal is apparently located on the surface of the particles. It is known that silver is a very reactive noble element and can form silver oxide under ambient conditions. For example, reports on the existence of a few monolayers of $\mathrm{AgO}$ on silver exist [45]. As mentioned in the experimental section, sputtering of $\mathrm{Ag}$ on the $\mathrm{Gd}_{2} \mathrm{O}_{3}$ surface was performed under vacuum and $\mathrm{Ar}$ atmosphere, the oxidation of $\mathrm{Ag}$ is considered to occur in aerated conditions during the handling of the sample before measurement. For detailed statistics, Ag Auger parameters need to be calculated. Unfortunately, the peak position of Ag M4N45N45 Auger peak is around $1130 \mathrm{eV}$ [46] which is outside the range of the detector used in this study (Range: $0-1000 \mathrm{eV}$ ). Figure $6 \mathrm{c}$ and d present the XPS survey and high-resolution spectra of $\mathrm{Au} 4 \mathrm{f}$ in $\mathrm{Gd}_{2} \mathrm{O}_{3} @ \mathrm{Au}$ system, respectively. The new intense peak at $335.3 \mathrm{eV}$ results from the Au layer sputtered on the surface of particles, while the original peaks of $\mathrm{Gd}_{2} \mathrm{O}_{3}$ became less intense. In Fig. $6 \mathrm{~d}$, the $\mathrm{Au} 4 \mathrm{f}$ curve fitting of the $\mathrm{Au} / \mathrm{Gd}_{2} \mathrm{O}_{3}$ sample displayed two $\mathrm{Au} 4 \mathrm{f}$ components at 84.35 and $88.02 \mathrm{eV}$, which correspond to $\mathrm{Au} 4 \mathrm{f} 5 / 2$ and $\mathrm{Au} 4 \mathrm{f} 7 / 2$ spin-orbit component, respectively. $[47,48]$ The difference in binding energy of $3.7 \mathrm{eV}$ between the Au 4f 7/2 and Au 4f 5/2 peaks and the FWHM of fitted peaks $(<0.9 \mathrm{eV})$ further emphasize the presence of Au metal on the particles surface. The calculated peak ratio of $3 d 7 / 2: 3 d 5 / 2$ for $\mathrm{Au}$ in the fitting spectra is close 

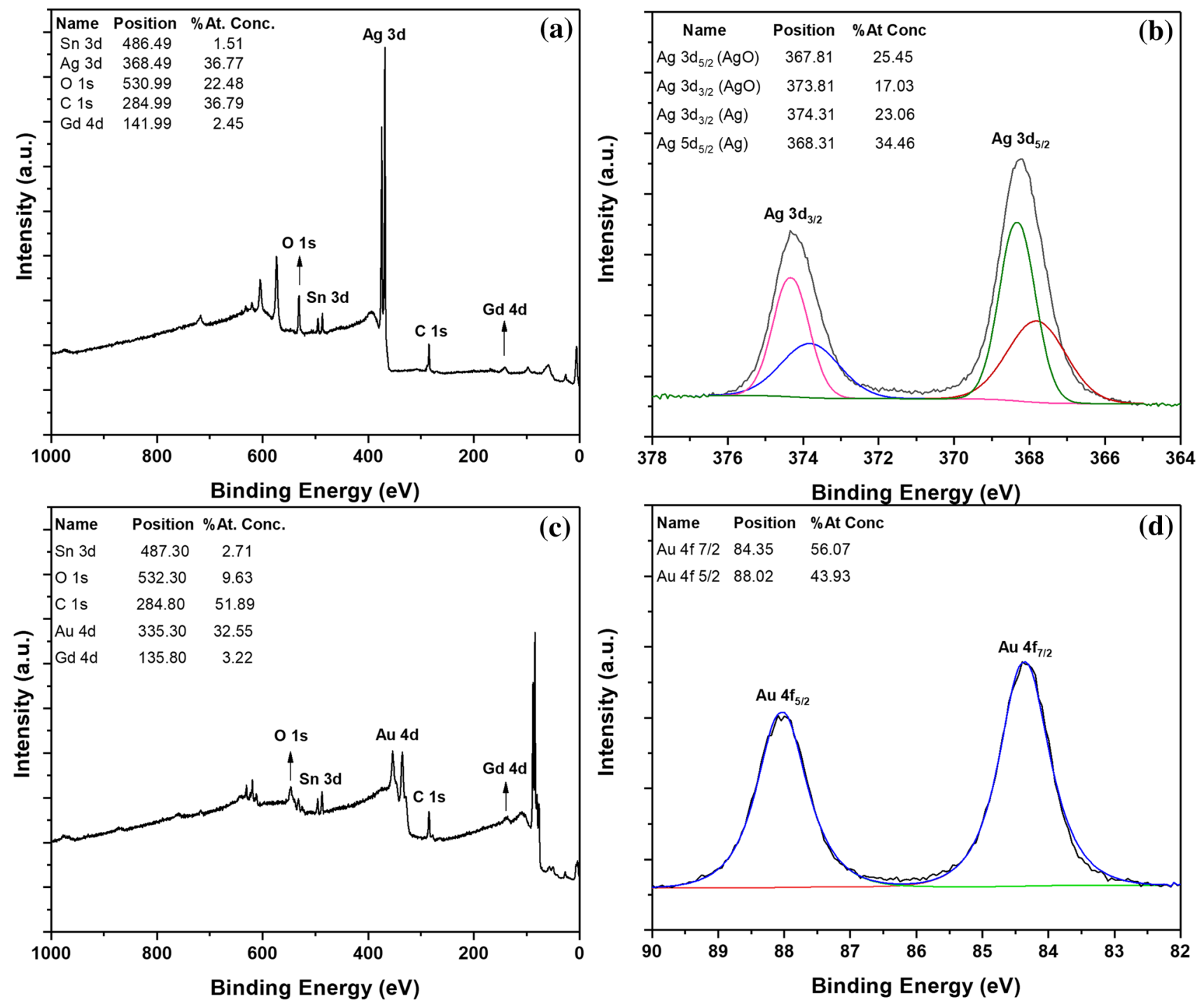

Fig. 6 a XPS survey spectrum of $\mathrm{Gd}_{2} \mathrm{O}_{3} @ \mathrm{Ag}$ and $\mathbf{b}$ High-resolution $\mathrm{Ag} 3 \mathrm{~d}$ spectra of the $\mathrm{Gd}_{2} \mathrm{O}_{3} @ \mathrm{Ag}$ particles (line shape of fitting: $\mathrm{AgO}$ GL(20), Ag GL(20) T(S.S). c XPS survey spectrum of $\mathrm{Gd}_{2} \mathrm{O}_{3} @ \mathrm{Au}$ and d High-resolution $\mathrm{Au} 4 \mathrm{f}$ spectra of the $\mathrm{Gd}_{2} \mathrm{O}_{3} @ \mathrm{Au}$ particles

[line shape of fitting: GL (82) T (S.S)]. While an oxide formation is detected in case of $\mathrm{Gd}_{2} \mathrm{O}_{3} @ \mathrm{Ag}$ particles, no oxide is measured for $\mathrm{Gd}_{2} \mathrm{O}_{3} @$ Au particles

to $4: 3$, the area ratio of $f$ subshell. In contrast to $\mathrm{Gd}_{2} \mathrm{O}_{3} @ \mathrm{Ag}$ particles, no peak corresponding to gold oxide was detected. Since $\mathrm{Au}$ is less prone to oxidation then $\mathrm{Ag}$, it was long considered a completely inert metal, and the oxidation of Au by $\mathrm{O}_{2}$ without additional heating is not favored [49].

\section{Further functionalization of silica Janus-type particles}

As already reported by our group [16], click chemistry has a high potential for the bioconjugation of NPs. To investigate the applicability of $\mathrm{SiO}_{2}-\mathrm{N}_{3} @$ Au particles presented here, a model molecule (5-Carboxyfluorescein, 5-FAM) was selectively attached to the azide functionalized side of the particles via a copper catalyzed click reaction [50].

Spectroscopical methods (UV-Vis, FT-IR) prove the successful attachment of the dye, as presented in Fig. 7. The disappearance of the characteristic azide band at $2100 \mathrm{~cm}^{-1}$ in the FT-IR spectrum (Fig. 7b) after the click reaction (violet) clarifies a successful surface modification. In addition, at 1435 and $1450 \mathrm{~cm}^{-1}, 1,2,3$-triazole bands [16] could be observed. Furthermore, absorption bands related to the triazole [51] and 5-FAM [52] were measured in the UV-Vis spectrum (Fig. 7a) at 230 and $425 \mathrm{~nm}$, respectively, whereas no plasmonic signal was detected. Most likely, the surface plasmon resonance is hindered by the attached dye. 

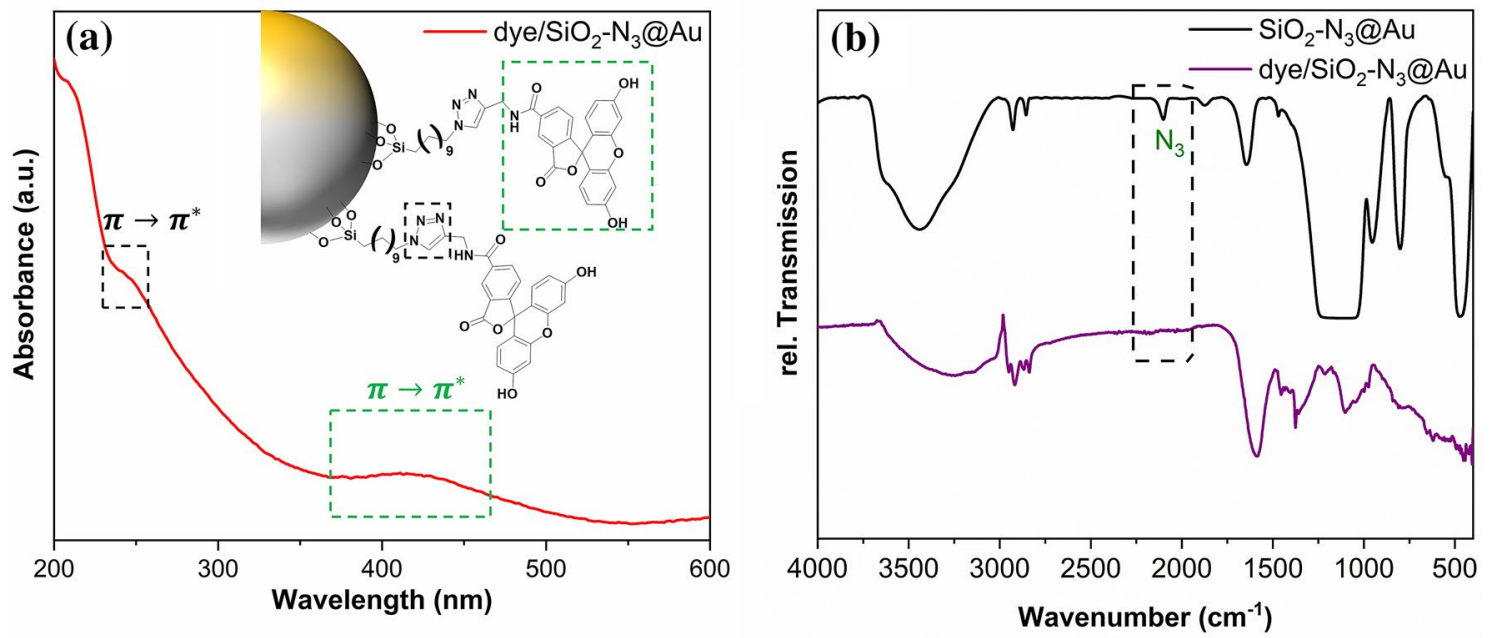

Fig. 7 UV-Vis (a) and FT-IR (b) spectra of dye functionalized $\mathrm{Au} @ \mathrm{SiO}_{2}-\mathrm{N}_{3}$ particles. A clear absorption of 5-FAM is detected, while the characteristic absorption band for azides is vanishing in FT-IR measurement

\section{Conclusion}

Plasmonic silver and gold NPs were successfully immobilized on phase pure $\mathrm{Gd}_{2} \mathrm{O}_{3}$ and functionalized silica spheres, leading to the formation of non-centrosymmetric dispersable systems. In contrast to literature reports, no adhesive interlayer was needed to guarantee an intimate contact at the NP-metal interface, still present after weeks, as proven by SEM and TEM. UV-Vis spectroscopy revealed a plasmonic activity for $\mathrm{Gd}_{2} \mathrm{O}_{3} @ \mathrm{Ag}, \mathrm{Gd}_{2} \mathrm{O}_{3} @ \mathrm{Au}$, and $\mathrm{SiO}_{2}-\mathrm{N}_{3} @ \mathrm{Au}$. In case of $\mathrm{Gd}_{2} \mathrm{O}_{3} @ \mathrm{Ag}$ and $\mathrm{Gd}_{2} \mathrm{O}_{3} @ \mathrm{Au}$, the red shift of the absorption bands was explained by shell effects, such as variations in roughness and the presence of nanoclusters. In addition, XPS analysis proved the metallic character of the silver and gold NPs, only a few oxidized AgO species were observed, which could be attributed to the exposure of the sputtered sample to aerated conditions. Further functionalization of $\mathrm{SiO}_{2}-\mathrm{N}_{3} @$ Au with a model molecule (5-FAM) via click chemistry was successfully performed and proven by UV-Vis and FT-IR spectroscopy. Our results demonstrate that this synthesis route avoids the use of expensive reagents and solvents and is capable of generating functional layers on sub-micrometer sized particles without additional adjustments. Furthermore, we prove the applicability of the presented approach to a variety of crystalline and amorphous systems, providing new possibilities in material and interface engineering.

Acknowledgements The authors would like to thank the University of Cologne (Excellence Program "Quantum Matter and Materials"), the "Deutsche Forschungsgemeinschaft" (DFG) and the "Deutscher
Akademischer Austauschdienst" (DAAD) for financial support. S. Öz gratefully acknowledges the financial support provided by Merck KGaA (Darmstadt). In addition, we are thankful to Dipl.-Phys. Raphael German for Raman spectroscopy measurements, Mrs. Nurgül Tosun and Dr. Stefan Roitsch for SEM and TEM measurements.

\section{Compliance with ethical standards}

Conflict of interest The authors declare no competing financial interest.

Open Access This article is distributed under the terms of the Creative Commons Attribution 4.0 International License (http://creativeco mmons.org/licenses/by/4.0/), which permits unrestricted use, distribution, and reproduction in any medium, provided you give appropriate credit to the original author(s) and the source, provide a link to the Creative Commons license, and indicate if changes were made.

\section{References}

1. Perro, A., Reculusa, S., Ravaine, S., Bourgeat-Lami, E., Duguet, E.: Design and synthesis of janus micro-and nanoparticles. J. Mater. Chem. 15, 3745-3760 (2005)

2. Chen, Y., Yang, D., Yoon, Y.J., Pang, X., Wang, Z., Jung, J., He, Y., Harn, Y.W., He, M., Zhang, S.: Hairy uniform permanently ligated hollow nanoparticles with precise dimension control and tunable optical properties. J. Am. Chem. Soc. 139, 12956-12967 (2017)

3. Hemmer, E., Acosta-Mora, P., Méndez-Ramos, J., Fischer, S.: Optical nanoprobes for biomedical applications: shining a light on upconverting and near-infrared emitting nanoparticles for imaging, thermal sensing, and photodynamic therapy. J. Mater. Chem. B 5, 4365-4392 (2017) 
4. Zhu, S., Meng, Q., Wang, L., Zhang, J., Song, Y., Jin, H., Zhang, K., Sun, H., Wang, H., Yang, B.: Highly photoluminescent carbon dots for multicolor patterning, sensors, and bioimaging. Angew. Chem. 125, 4045-4049 (2013)

5. Halas, N.: Playing with plasmons: tuning the optical resonant properties of metallic nanoshells. MRS Bull. 30, 362-367 (2005)

6. Xu, W., Miao, X., Oh, I.T., Chae, K.S., Cha, H., Chang, Y., Lee, G.H.: Dextran-coated ultrasmall $\mathrm{Gd}_{2} \mathrm{O}_{3}$ nanoparticles as potential T1 MRI contrast agent. ChemistrySelect 1, 6086-6091 (2016)

7. Huang, H., Weng, L., Golzarian, J.: Optimizing contrast effect in T1-weighted magnetic resonance imaging of $\mathrm{Gd}_{2} \mathrm{O}_{3}$-based nanoagent via dopamine chelation. Neurosci. Biomed. Eng. 4, 249-254 (2016)

8. Chen, Y., Gan, T., Ma, C., Wang, L., Zhang, G.: Crystallization of polymer chains chemically attached on a surface: lamellar orientation from flat-on to edge-on. J. Phys. Chem. B 120, 4715-4722 (2016)

9. Liang, L., Astruc, D.: The copper (I)-catalyzed alkyne-azide cycloaddition (CuAAC) "click" reaction and its applications. An overview. Coord. Chem. Rev. 255, 2933-2945 (2011)

10. Presolski, S.I., Hong, V.P., Finn, M.: Copper-catalyzed azidealkyne click chemistry for bioconjugation. Curr. Protoc. Chem. Biol. 3, 153-162 (2011)

11. Kolb, H.C., Finn, M., Sharpless, K.B.: Click chemistry: diverse chemical function from a few good reactions. Angew. Chem. Int. Ed. 40, 2004-2021 (2001)

12. Song, E.-Q., Hu, J., Wen, C.-Y., Tian, Z.-Q., Yu, X., Zhang, Z.-L., Shi, Y.-B., Pang, D.-W.: Fluorescent-magnetic-biotargeting multifunctional nanobioprobes for detecting and isolating multiple types of tumor cells. ACS Nano 5, 761-770 (2011)

13. Kuhn, S.J., Finch, S.K., Hallahan, D.E., Giorgio, T.D.: Proteolytic surface functionalization enhances in vitro magnetic nanoparticle mobility through extracellular matrix. Nano Lett. 6, 306-312 (2006)

14. Sudimack, J., Lee, R.J.: Targeted drug delivery via the folate receptor. Adv. Drug Deliv. Rev. 41, 147-162 (2000)

15. Bolley, J., Guenin, E., Lievre, N., Lecouvey, M., Soussan, M., Lalatonne, Y., Motte, L.: Carbodiimide versus click chemistry for nanoparticle surface functionalization: a comparative study for the elaboration of multimodal superparamagnetic nanoparticles targeting $\alpha v \beta 3$ integrins. Langmuir 29, 14639-14647 (2013)

16. Ilyas, S., Ilyas, M., van der Hoorn, R.A., Mathur, S.: Selective conjugation of proteins by mining active proteomes through click-functionalized magnetic nanoparticles. ACS Nano 7, 9655-9663 (2013)

17. Koo, H., Lee, S., Na, J.H., Kim, S.H., Hahn, S.K., Choi, K., Kwon, I.C., Jeong, S.Y., Kim, K.: Bioorthogonal copper-free click chemistry in vivo for tumor-targeted delivery of nanoparticles. Angew. Chem. Int. Ed. 51, 11836-11840 (2012)

18. Lal, S., Clare, S.E., Halas, N.J.: Nanoshell-enabled photothermal cancer therapy: impending clinical impact. Acc. Chem. Res. 41, 1842-1851 (2008)

19. Hu, S.-H., Gao, X.: Nanocomposites with spatially separated functionalities for combined imaging and magnetolytic therapy. J. Amer. Chem. Soc. 132, 7234-7237 (2010)

20. Xu, C., Xie, J., Ho, D., Wang, C., Kohler, N., Walsh, E.G., Morgan, J.R., Chin, Y.E., Sun, S.: $\mathrm{Au}-\mathrm{Fe}_{3} \mathrm{O}_{4}$ dumbbell nanoparticles as dual-functional probes. Angew. Chem. 120, 179-182 (2008)

21. Ebbens, S.J., Howse, J.R.: Direct observation of the direction of motion for spherical catalytic swimmers. Langmuir 27, 1229312296 (2011)

22. Kumar, A., Park, B.J., Tu, F., Lee, D.: Amphiphilic janus particles at fluid interfaces. Soft Matter 9, 6604-6617 (2013)
23. Chen, Q., Whitmer, J.K., Jiang, S., Bae, S.C., Luijten, E., Granick, S.: Supracolloidal reaction kinetics of janus spheres. Science 331, 199-202 (2011)

24. Walther, A., Drechsler, M., Rosenfeldt, S., Harnau, L., Ballauff, M., Abetz, V., Müller, A.H.: Self-assembly of janus cylinders into hierarchical superstructures. J. Amer. Chem. Soc. 131, 4720-4728 (2009)

25. Kaewsaneha, C., Tangboriboonrat, P., Polpanich, D., Eissa, M., Elaissari, A.: Janus colloidal particles: preparation, properties, and biomedical applications. ACS Appl. Mater. Interfaces. 5, 1857-1869 (2013)

26. Walther, A., Müller, A.H.: Janus particles: synthesis, self-assembly, physical properties, and applications. Chem. Rev. 113, 51945261 (2013)

27. Casagrande, C., Veyssie, M.: «Grains janus »: réalisation et premières observations des propriétés interfaciales. C. R. Acad. Sci. (Paris) 306, 1423-1425 (1988)

28. Lu, Y., Xiong, H., Jiang, X., Xia, Y., Prentiss, M., Whitesides, G.M.: Asymmetric dimers can be formed by dewetting half-shells of gold deposited on the surfaces of spherical oxide colloids. J. Amer. Chem. Soc. 125, 12724-12725 (2003)

29. Love, J.C., Gates, B.D., Wolfe, D.B., Paul, K.E., Whitesides, G.M.: Fabrication and wetting properties of metallic half-shells with submicron diameters. Nano Lett. 2, 891-894 (2002)

30. Hsu, W.P., Ronnquist, L., Matijevic, E.: Preparation and properties of monodispersed colloidal particles of lanthanide compounds. 2. cerium (IV). Langmuir 4, 31-37 (1988)

31. Stöber, W., Fink, A., Bohn, E.: Controlled Growth of monodisperse silica spheres in the micron size range. J. Colloid Interface Sci. 26, 62-69 (1968)

32. Claesson, E., Philipse, A.: Monodisperse magnetizable composite silica spheres with tunable dipolar interactions. Langmuir 21, 9412-9419 (2005)

33. Cho, H.-S., Dong, Z., Pauletti, G.M., Zhang, J., Xu, H., Gu, H., Wang, L., Ewing, R.C., Huth, C., Wang, F.: Fluorescent, superparamagnetic nanospheres for drug storage, targeting, and imaging: a multifunctional nanocarrier system for cancer diagnosis and treatment. ACS Nano 4, 5398-5404 (2010)

34. Di, W., Ren, X., Zhao, H., Shirahata, N., Sakka, Y., Qin, W.: Single-phased luminescent mesoporous nanoparticles for simultaneous cell imaging and anticancer drug delivery. Biomaterials 32, 7226-7233 (2011)

35. Hesse, M., Meier, H., Zeeh, B.: Spektroskopische methoden in der organischen chemie. Georg Thieme Verlag, Stuttgart (2005)

36. Hunter, R.J.: Zeta potential in colloid science: principles and applications. Academic press, London (2013)

37. Vivero-Escoto, J.L., Huxford-Phillips, R.C., Lin, W.: Silicabased nanoprobes for biomedical imaging and theranostic applications. Chem. Soc. Rev. 41, 2673-2685 (2012)

38. Myroshnychenko, V., Rodríguez-Fernández, J., Pastoriza-Santos, I., Funston, A.M., Novo, C., Mulvaney, P., Liz-Marzán, L.M., de Abajo, F.J.G.: Modelling the optical response of gold nanoparticles. Chem. Soc. Rev. 37, 1792-1805 (2008)

39. Canet-Ferrer, J., Albella, P., Ribera, A., Usagre, J.V., Maier, S.A.: Hybrid magnetite-gold nanoparticles as bifunctional magnetic-plasmonic systems: three representative cases. Nanoscale Horiz. 2, 205-216 (2017)

40. Wang, H., Goodrich, G.P., Tam, F., Oubre, C., Nordlander, P., Halas, N.J.: Controlled texturing modifies the surface topography and plasmonic properties of Au nanoshells. J. Phys. Chem. B 109, 11083-11087 (2005)

41. Lupták, R., Fröhlich, K., Rosová, A., Hušeková, K., Ťapajna, M., Machajdík, D., Jergel, M., Espinós, J., Mansilla, C.: Growth of gadolinium oxide films for advanced MOS structure. Microelectron. Eng. 80, 154-157 (2005) 
42. X-ray Photoelectron Spectroscopy, Ferraria, A.M., Carapeto, A.P., do Rego, A.M.B.: X-ray photoelectron spectroscopy: silver salts revisited. Vacuum 86, 1988-1991 (2012)

43. Bhunia, S.K., Jana, N.R.: Reduced graphene oxide-silver nanoparticle composite as visible light photocatalyst for degradation of colorless endocrine disruptors. ACS Appl. Mater. Interfaces. 6, 20085-20092 (2014)

44. Weaver, J.F., Hoflund, G.B.: Surface characterization study of the thermal decomposition of AgO. J. Phys. Chem. 98, 85198524 (1994)

45. Erol, M., Han, Y., Stanley, S.K., Stafford, C.M., Du, H., Sukhishvili, S.: SERS not to be taken for granted in the presence of oxygen. J. Amer. Chem. Soc. 131, 7480-7481 (2009)

46. Muddiman, D.C., Brockman, A.H., Proctor, A., Houalla, M., Hercules, D.M.: Characterization of polystyrene on etched silver using ion scattering and X-ray photoelectron spectroscopy: correlation of secondary ion yield in time-of-flight sims with surface coverage. J. Phys. Chem. 98, 11570-11575 (1994)

47. Turner, N., Single, A.: Determination of peak positions and areas from wide-scan XPS spectra. Surf. Interface Anal. 15, 215-222 (1990)

48. Eremenko, A., Smirnova, N., Gnatiuk, I., Linnik, O., Vityuk, N., Mukha, Y., Korduban, A.: Silver and gold nanoparticles on
Sol-Gel $\mathrm{TiO}_{2}, \mathrm{ZrO}_{2}, \mathrm{SiO}_{2}$ surfaces: optical Spectra, photocatalytic activity, bactericide properties. In: Cuppoletti, J. (ed.) Nanocomposites and polymers with analytical methods. InTech, Rijeka, Croatia (2011)

49. Mihaylov, M., Ivanova, E., Hao, Y., Hadjiivanov, K., Gates, B.C., Knötzinger, H.: Oxidation by $\mathrm{CO}_{2}$ of $\mathrm{Au}_{0}$ species on $\mathrm{La}_{2} \mathrm{O}_{3}$-supported gold clusters chem. Chem. Comm. 175, 18973 (2008)

50. Kolb, H.C., Finn, M., Sharpless, K.B.: Click-chemie: diverse chemische funktionalität mit einer handvoll guter reaktionen. Angew. Chem. 113, 2056-2075 (2001)

51. Schweinfurth, D., Pattacini, R., Strobel, S., Sarkar, B.: New 1, 2, 3 -triazole ligands through click reactions and their palladium and platinum complexes. Dalton Trans. 42, 9291-9297 (2009)

52. Grignon, N., Touraine, B., Durand, M.: 6 (5) Carboxyfluorescein as a tracer of phloem sap translocation. Am. J. Bot. 76, 871-877 (1989)

Publisher's Note Springer Nature remains neutral with regard to urisdictional claims in published maps and institutional affiliations. 